\title{
Effects of an Educational Intervention Based on the Protection Motivation Theory and Implementation Intentions on First and Second Pap Test Practice in Iran
}

\author{
Tahereh Dehdari ${ }^{1}$,Laleh Hassani ${ }^{1 *}$, Ebrahim Hajizadeh ${ }^{2}$, Davoud Shojaeizadeh ${ }^{3}$, \\ Saharnaz Nedjat ${ }^{4}$, Mehrandokht Abedini ${ }^{5}$
}

\begin{abstract}
Background: Few Iranian women take the Papanicolaou test despite its important role in preventing cervical cancer. This study aimed to determine the effectiveness of an educational intervention based on the protection motivation theory (PMT) variables and implementation intentions in the first and second Pap test practice among Iranian women. Materials and Methods: In this quasi-randomized controlled trial, 200 women who were referred to 30 primary health care clinics in Tehran were randomly selected. PMT variables and Pap test practice were measured at baseline and again after 3 and 15 months. The 4-week educational intervention program was conducted for the intervention group. Results: Following the intervention, the mean scores of self-efficacy, perceived vulnerability, and behavior intention variables were significantly higher in the intervention group when compared to the control group $(\mathbf{p}<\mathbf{0 . 0 5})$. No significant differences were found in the perceived severity, response efficacy, response cost, and fear between the two groups following the intervention. Higher percent of women in the intervention group had obtained first and second Pap test compared to the controls. Conclusions: The PMT and implementation intentions provide a suitable theory-based framework for developing educational interventions regarding Pap test practice in Iran.
\end{abstract}

Keywords: Protection motivation theory - pap test - educational studies - implementation intentions - Iran

Asian Pac J Cancer Prev, 15 (17), 7257-7261

\section{Introduction}

Cervical cancer is the second most common cancer (Mortazavi et al., 2000) and the most common gynecological cancer in Iranian females (Behtash et al., 2005). The prevalence of this cancer was estimated 6-7 per 100,000 in Iran in 2006 (Society of Gynecologic Oncologists, 2006). However, the Papanicolaou test has been recognized as an easy and powerful screening test for early detection of the cervical cancer in the premalignant stage and its timely treatment (Jelfs, 1995), only $27.1 \%$ of the Iranian women have reported getting at least one Pap smear in their lifetime (Rezaie-Chamani et al., 2012).

Previous researches have identified barriers and facilitators associated with Pap test practice among Asian women, especially Iranian women (Allahverdipour and Emami, 2008; Othman et al., 2009; Abdullah and Su TT, 2010; Akbari et al., 2010; Erbil et al., 2010; RezaieChamani et al., 2012; Wongwatcharanukul et al., 2014). The lack of intervention efforts to address these factors is felt. Theory-based educational interventions are needed to provide the required information about cervical screening, modifying maladaptive beliefs, and increasing the rate of regular Pap test practice among women (Markovic et al., 2005; Gu et al., 2012; Demirtas and Acikgoz, 2013). In this study, the Protection Motivation Theory (PMT) and implementation intentions was considered as the conceptual framework for developing a tailored educational intervention. PMT was introduced by Rogers as a predictive theoretical model of health behaviors. This theory proposes that two appraisal processes, i.e. threat and coping appraisal, occur when the individual receives threatening information. Threat appraisal is associated with a maladaptive response. It involves the perceived severity of a threatening event and personal vulnerability to the proposed threat. Coping appraisal is associated with the proposed health recommendations and is affected by the individual's assessment of the effectiveness of the proposed recommended behavior to avert the danger (i.e. response efficacy) and the

${ }^{1}$ Department of Health Education and Health Promotion, Faculty of Health, Iran University of Medical Sciences, ${ }^{2}$ Department of Biostatistics, Faculty of Medical Sciences, Tarbiat Modares University, ${ }^{3}$ Department of Health Education and Health Promotion, Faculty of Health, Tehran University of Medical Sciences, ${ }^{4}$ Department of Epidemiology and Biostatistics, Faculty of Public Health, Knowledge Utilization Research Center, Tehran University of Medical Sciences, ${ }^{5}$ Department of Family Health, Ministry of Health and Medical Education, Tehran, Iran ${ }^{\circledR} E q u a l$ contributors *For correspondence: l-hassani@razi.tums.ac.ir 
perceived ability to practice the recommended behavior (i.e. perceived self-efficacy). Protection motivation (or behavior intention) is determined by the sum of factors increasing the likelihood of an adaptive response less than that of the variables diminishing that likelihood (Rogers, 1975; Mcmat and Prentice-Dunn, 2005). However, the motivation to carry out a behavior does not automatically translate into action. Over the recent years, researchers have performed investigations regarding the volitional processes involved in behavioral enactment (Milne et al., 2002). Recently, the concept of implementation intentions as one of the volitional strategies has received more empirical evidence (Gollwitzer et al., 1997). It is suggested that motivational models such as PMT could be usefully strengthened through volitional strategies (e.g. implementation intentions) in order to enhance the likelihood of the translation of the goal intention into performing recommended precautionary health behavior (Milne et al., 2002). Implementation intentions mediate the relationship between the goal intention and behavior (Sheeran and Orbell, 2000) and increase commitment to do the target behaviors (Gollwitzer et al., 1993). Although PMT and implementation intentions are recommended as a suitable theoretical framework for developing interventions regarding preventive behaviors of cancer, especially cervical cancer screening (Glance et al., 2008), few studies have used the theories in this field (McClendon and Prentice-Dunn, 2001; Steadman and Quine, 2004; Fry and Prentice-Dunn, 2006; Rutter et al., 2006). For example, Fry and Prentice-Dunn and McClendon and Prentice-Dunn in the two studies showed that developing intervention based on PMT could encourage women to performing breast self -examination (Fry and PrenticeDunn, 2006) and modifying maladaptive attitudes and behaviors in terms of skin cancer risk, respectively (McClendon and Prentice-Dunn, 2001). Steadman and Quine and Rutter et al found that interventions based on implementation intentions can encourage men and women to perform testicular self-examination (Steadman and Quine, 2004) and mammography (Rutter et al., 2006), respectively.

Therefore, given the advantages of education in changing the women's maladaptive beliefs and attitudes about the Pap test and the lack of intervention studies in this field, the present study was undertaken to examine the effect of a PMT- and implementation intentions-based educational intervention on increasing the first and second Pap test practice among a sample of Iranian women.

\section{Materials and Methods}

\section{Design and sample}

This quasi-randomized controlled trial study was conducted from July 2012 to Jun 2014 in Tehran, Iran. A convenience sample of 240 women was randomly chosen from 30 primary health care clinics affiliated with Tehran University of Medical Sciences (8 women from each clinic). Women from 15 clinics were assigned into the intervention group, while those from the remaining 15 clinics were assigned to the control group. Selection criteria were as follows: 1) no diagnosis of cervical cancer;
2) being married or sexually active; 3 ) no history of the Pap test or previous full uterus hysterectomy; and 4) ability to read and write in Farsi. The present study was approved by the ethics committee of Tehran University of Medical Sciences and written informed consent was obtained from all the participants. Twenty-three participants in the intervention group and 17 in the control group refused to take part in the study and finally, there were 97 women in the intervention group and 103 in the control group.

\section{Procedure}

A valid and reliable 26-item tool was used for assessing the PMT variables in terms of the first Pap test practice (Hassani et al., 2014). Two groups completed the questionnaires prior to the intervention. Based on the findings of pre-test of groups, an educational intervention was developed for women in the intervention group. Finally, both groups were followed and assessed 3 and 15 months after the intervention.

\section{Study instrument and measures}

Demographic variables,PMT items, and implementation intentions were measured by questionnaires which took 20 to 25 minutes to complete. In the tool that was used for assessing the PMT variables in terms of the first Pap test practice (Hassani et al., 2014), 3 items were used for evaluating the intention, 3 items for perceived vulnerability, 4 items for perceived severity, 3 items for fear, 2 items for response cost, 4 items for response efficacy, and 7 items for self-efficacy. The first six items were measured on a Likert scale ranging from $1=$ completely disagree to $5=$ completely agree. Self-efficacy regarding Pap test practice were measured on a Likert-type scale ranging from $1=$ completely unconfident to 5 completely confident. Having the Pap test was followed using the recorded Pap test result in the family health record for each participant. According the proposed procedure by Gollwitzer (Gollwitzer, 1993), implementation intentions was measured by asking the women "Have you committed

Table 1. Descriptive Statistics (Means (SD) and Percentages) in the Intervention $(n=97)$ and the Control Group $(n=103)$

\begin{tabular}{|c|c|c|}
\hline Variable & $\begin{array}{l}\text { Control group } \\
\quad(n=103)\end{array}$ & $\begin{array}{l}\text { Intervention group } \\
\qquad(\mathrm{n}=97)\end{array}$ \\
\hline Age $($ Mean \pm SD $)$ & $38.82 \pm 8.08$ & $37.99 \pm 8.16$ \\
\hline Age at marriage $($ mean $\pm S D)$ & $20.40 \pm 4.7$ & $19.61 \pm 4.41$ \\
\hline \multicolumn{3}{|l|}{ Number of children, $\mathrm{N}(\%)$} \\
\hline$\leq 2$ & $80(77.7 \%)$ & $67(69.1 \%)$ \\
\hline$>2$ & $23(22.3 \%)$ & $30(30.9 \%)$ \\
\hline \multicolumn{3}{|l|}{ Number of pregnancies, $\mathrm{N}(\%)$} \\
\hline$\leq 2$ & $68(66 \%)$ & $51(52.6 \%)$ \\
\hline$>2$ & $35(34 \%)$ & $46(47.4 \%)$ \\
\hline \multicolumn{3}{|l|}{ Number of deliveries, $\mathrm{N}(\%)$} \\
\hline$\leq 2$ & $81(78 / 6 \%)$ & $68(70.1 \%)$ \\
\hline$>2$ & $22(21.4 \%)$ & $29(29.9 \%)$ \\
\hline \multicolumn{3}{|c|}{ Occupational status status, $\mathrm{N}(\%)$} \\
\hline Self-employed & $5(4.86 \%)$ & $3(3.09 \%)$ \\
\hline Employed & $6 \quad(5.82 \%)$ & $2(2.06 \%)$ \\
\hline Housewife & $92(89.32 \%)$ & $92(94.85 \%)$ \\
\hline \multicolumn{3}{|l|}{ Educational level, N(\%) } \\
\hline Illitrate & $3(2.92 \%)$ & $3(3.09 \%)$ \\
\hline$\leq 12^{\text {th }}($ grade $)$ & $50(48.54 \%)$ & $46(47.42 \%)$ \\
\hline$>12^{\text {th }}$ (grade $)$ & $50(48.54 \%)$ & $48(49.49 \%)$ \\
\hline
\end{tabular}


yourself to Pap test practice? Please write down the date and where you will perform the first/second Pap test."

\section{Developed educational intervention}

The educational intervention was developed based on the two groups' pre-tests findings. The educational intervention involved four 60-minute sessions conducted during a four-week period for the women in the intervention group. During the sessions, the participants were divided into small groups and received tailored instructions for Pap test practice through group discussions, lectures, and question and answer sessions. The purpose of the first session was to increase the perceived severity of the women about cervical cancer and its various effects on the life of the women. In this session, women's maladaptive beliefs regarding lack of vulnerability to cervical cancer were discussed. The second training session was an introduction to the importance of the Pap test and its advantages in early detection and timely treatment of cervical cancer were explained. At the end of this session, an instructional booklet was given to the women. In addition, women were asked to record their response to this question: "If you are going to get your first and second Pap test during the next 3 and 15 months, write down where and when you are going to get the test. Also, participants were asked to write down the problems that they had to get a Pap test. In the third session, besides discussions about the costs of the Pap test, the participants were instructed on ways of overcoming barriers of getting the Pap test. In the fourth session, by open-ended questions, the women were asked to reflect their experiences and positive or negative feelings (e.g. fear of the Pap test procedure or fear of knowing about a confirmed lesion in the reproductive organ) toward the Pap test and its perceived advantages/disadvantages. In this session, the women were assured that they could get Pap test regularly.

\section{Data analysis}

Data were analyzed using the SPSS statistical software package (SPSS Inc., Chicago, IL, USA). The homogeneity of the baseline data in demographic characteristics and PMT variables of the two groups was analyzed by $\chi^{2}$ and independent-samples $t$ tests. The normality of the data was also examined using the Kolmogorov-Smirnov test. Differences between the baseline and the three-month assessments and those documented fifteen months after the intervention in each group and between the groups were tested using repeated measurement analysis. Chi-square was used to identify significant differences in the number of Pap test practice between the groups before, and 3 and 15 months after the intervention. The data were expressed as mean \pm SD. $p$ values $<0.05$ were considered significant.

\section{Results}

\section{Demographic characteristics of the participants}

The mean age (SD) of the women in the intervention and control groups was 37.9 (8) and 38.8 (8) years, respectively. Demographic characteristics of the two groups are presented in Table 1. Prior to the intervention, no significant differences were found between the demographic characteristics of the groups $(\mathrm{p}<0.05)$.

Comparison of differences in PMT variables at baseline and after three and fifteen months of follow-up

Prior to the interventions, no significant differences in PMT variables were found between the two groups $(\mathrm{p}<0.05)$. As shown in Table 2 , the results showed that following the intervention, the intervention group had higher total mean scores of self-efficacy, perceived vulnerability and behavior intention in compared to the control group $(\mathrm{p}<0.05)$. In addition, three months and fifteen months after the intervention, the mean scores of fear, response cost, perceived severity, and response efficacy regarding the Pap test were not significantly different between the two groups $(\mathrm{p}>0.05)$ (Table 2). The results of the present study showed that after the

Table 2. Comparison of PMT Variables before and Three and Fifteen Months after the Intervention in the Intervention $(\mathbf{n = 9 7})$ and the Control Group $(\mathbf{n = 1 0 3})$

\begin{tabular}{lcccccc}
\hline & \multicolumn{2}{c}{$\begin{array}{c}\text { Pre-intervention } \\
\text { Control group }\end{array}$} & $\begin{array}{c}\text { Three-months after intervention } \\
\text { Intention group }\end{array}$ & $\begin{array}{c}\text { Fifteen-months after intervention } \\
\text { Control group }\end{array}$ & Intervention group & Control group Intervention group \\
\hline Perceived vulnerability & $11.33 \pm 3.04$ & $10.07 \pm 2.75$ & $11.14 \pm 3.11$ & $10.60 \pm 2.90$ & $11.17 \pm 3.16^{\beta}$ & $10.86 \pm 2.98^{\beta * *}$ \\
Perceived severity & $16.04 \pm 3.51$ & $15.93 \pm 3.60$ & $16.07 \pm 3.50$ & $15.81 \pm 3.80$ & $16.06 \pm 3.64^{\beta}$ & $15.93 \pm 3.94^{\beta}$ \\
Self-efficacy & $32.22 \pm 3.90$ & $31.78 \pm 3.26$ & $28.81 \pm 5.72$ & $31.59 \pm 5.69$ & $23.99 \pm 5.31^{\beta}$ & $33.62 \pm 2.79^{\beta * *}$ \\
Response efficacy & $18.22 \pm 2.66$ & $17.53 \pm 1.97$ & $18.74 \pm 1.95$ & $18.57 \pm 1.82$ & $18.67 \pm 2.30^{\beta}$ & $18.84 \pm 1.75^{\beta}$ \\
Response cost & $6.22 \pm 2.84$ & $6.718 \pm 2.96$ & $6.24 \pm 2.98$ & $5.91 \pm 3.09$ & $6.23 \pm 3.08^{\beta}$ & $5.64 \pm 3.12^{\beta}$ \\
Fear & $6.70 \pm 3.95$ & $6.38 \pm 3.99$ & $6.79 \pm 4.03$ & $6.44 \pm 4.13$ & $6.80 \pm 4.07^{\beta}$ & $6.25 \pm 4.19^{\beta}$ \\
Behavior intention & $13.42 \pm 2.10$ & $13.56 \pm 1.47$ & $13.27 \pm 1.66$ & $14.31 \pm 1.26$ & $13.14 \pm 1.82^{\beta}$ & $14.35 \pm 1.36^{\beta * *}$ \\
\hline
\end{tabular}

*1. Values are Mean \pm SD; 2. Result of Repeated Measures test; $\mathrm{p}^{\beta}<0.05$ compared to pre-intervention; 3 . Result of Repeated Measures test; $\mathrm{p}^{* *}<0.05$ compared to control group

Table 3. Frequency of first and second Pap test practice in the before and three and fifteen-months after the educational intervention in the intervention $(n=97)$ and the control group $(n=103)$

\begin{tabular}{|c|c|c|c|c|c|c|}
\hline & \multicolumn{2}{|c|}{ Pre-intervention } & \multirow{2}{*}{\multicolumn{2}{|c|}{$\begin{array}{l}\text { Three-months after intervention } \\
\text { (first Pap test) } \\
\text { Control group Intervention group }\end{array}$}} & \multirow{2}{*}{\multicolumn{2}{|c|}{$\begin{array}{l}\text { Fifteen-months after intervention } \\
\text { (second Pap test) } \\
\text { Control group Intervention group }\end{array}$}} \\
\hline & Control group & Intervention group & & & & \\
\hline Pap test practice & $0(0 \%)$ & $0(0 \%)$ & $10(9.7 \%)$ & $60(61.9 \%)$ & $0(0 \%)$ & $41(58.6 \%)^{\dagger * *}$ \\
\hline
\end{tabular}


intervention, significantly more women in the intervention group had obtained first and second Pap test $(61.9 \%$ at post-test 1 and $58.6 \%$ at post-test 2 ) compared to the control group (9.7\% at post-test 1 and no percent at posttest 2) (Table 3).

\section{Discussion}

The results of the present study showed that three and fifteen months after the intervention, a considerable increase occurred in the first and second Pap test practice in the intervention group when compared to the control. Our findings were consistent with those of similar studies (McClendon and Prentice-Dunn 2001; Fang et al., 2007; Park et al., 2005; Fry and Prentice-Dunn 2006; Chumworathayi et al., 2007; Yucel et al., 2009). A significant decrease was observed between the total number of women in the intervention group that had repeated Pap test at post-test 2 than post-test $1(58.6 \%$ vs $61.9 \%$ (Table 3 ), which shows that such factors may influence repeated Pap test. In line with this finding, FernaÂndez-Esquer et al reported that acculturation, Pap smear beliefs, health insurance, and demographic variables (e.g. age and marital status) were significantly associated with repeated Pap smear among low income Mexican-American women (FernaAndez-Esquer et al., 2003). Gu et al also indicated that previous Pap smear screening experiences may influence regular Pap test among Chinese women (Gu et al., 2013). More studies are required to identify factors influencing repeated Pap smear among Iranian women.

We found that the intervention considerably increased perceived vulnerability in the intervention group compared to the control group 3 and 15 months after the intervention. According to a report by Rezaie-Chamani et al., Iranian women have a lower perceived susceptibility regarding cervical cancer and believe that Pap test screening is unnecessary if there are no symptoms of cancer (RezaieChamani et al., 2012). Shekhar et al showed that nearly half of non screened Indian nursing staffs felt that they were not vulnerable to cervical cancer (Shekhar et al., 2013). In fact, women are more likely to receive the Pap test if they feel that they are vulnerable to cervical cancer. Therefore, perceived susceptibility, as one of the psychosocial predictors influencing regular Pap test practice among women, is a crucial element in constructing the cervical cancer screening program.

The results of the present study showed that the mean score of self-efficacy among women in the intervention group increased significantly following the intervention, which was consistent with the findings of a study conducted by Park et al. who reported that conducting an emotion-cognition focused program could improve perceived self-efficacy in Korean women regarding the Papanicolaou smear screening practice (Park et al., 2005). Beliefs in high personal self-efficacy to cervical cancer screening strongly decreased the perceived barriers of performing it. In line with it, Fang et al reported that lower perceived barriers and higher perceived self-efficacy were associated with Pap smear screening behavior among Korean women (Fang et al., 2007). Given the importance of self-efficacy to adopt cancer preventive behaviors, it is necessary that educational interventions be designed, taking into account the four sources of information (including mastery experiences, physiological state, verbal persuasion and vicarious experiences) affecting perceived self-efficacy (Bandura et al., 1977). Considering these resources may enhance self-efficacy of women for getting the Pap test and repeat it in the future. More efforts are needed to recognize the best methods of manipulating PMT variables within an educational intervention.

The results of this study showed that the intervention group had more intention to have the Pap test when compared to the control group after the intervention, which was consistent with the findings of similar studies (McClendon and Prentice-Dunn, 2001; Park et al., 2005). Therefore, PMT is a suitable theoretical framework for considering predictive factors of intention of women to attendance for Pap test. Accordingly, Helmes showed that applying the PMT variables was useful in identifying factors that play an important role in the women's intention to obtain genetic testing for the risk of breast cancer (Helmes, 2002).

The main strength of our study is that it was the first study that used PMT and implementation intentions for developing an educational intervention for increasing the first and second Pap test practice among Iranian women. The limitation of the present study is that data was collected from women who attended the primary health care clinics affiliated with Tehran University of Medical Sciences. Since these clinics are located in low-income areas of Tehran, this homogeneity of samples may limit the extent to which findings can be generalized to other groups (e.g. women in high and middle-income areas of Tehran). Similar studies are required in this field within other racial/ethnic groups and geographic areas in Iran.

In conclusion, the results of the present study showed that the PMT and implementation intentions-based educational intervention could increase the first and second Pap test practice among Iranian women.

\section{Acknowledgements}

This $\mathrm{Ph} . \mathrm{D}$ thesis was supported by Iran University of Medical Sciences, grant number 91-04-27-20508. The authors have no conflict of interest.

\section{References}

Abdullah AS, Leung TY (2001). Factors associated with the use of breast and cervical cancer screening services among chinese women in hong kong. Pub Health, 115, 212-7.

Abdullah F, Su TT (2010). Enhancement of the cervical cancer screening program in Malaysia: a qualitative study. Asian Pac J Cancer Prev, 11, 359-66.

Akbari F, Shakibazadeh E, Pourreza A, et al (2010). Barriers and facilitating factors for cervical cancer screening: A qualitative study from iran. Iran J Cancer Prev, 3, 178-84.

Allahverdipour H, Emami A (2008). Perceptions of cervical cancer threat, benefits, and barriers of Papanicolaou smear screening programs for women in iran. Women Health, 47, 23-37.

Announcement the society of gynecologic oncologists' statement 
on a cervix cancer vaccine (2006). Gynecol Oncol, 10,377.

Bandura A, Adams NE, Beyer J (1977). Experiental processes mediating behavioral change. J Pers Soc Psychol, 35, 125-39.

Behtash N, Ghaemmaghami F, Ayatollahi H, et al (2005). A case control study to evaluate urinary tract complications in radical hysterectomy. World J Surg Oncol, 3, 12.

Brian T. McClendon, Steven Prentice-Dunn (2001). Reducing skin cancer risk: an intervention sased on protection motivation theory. J Health Psychol, 6, 321-8.

Chumworathayi B, Yuenyao P, Luanratanakorn S, et al (2007). Can an appointment-letter intervention increase pap smear screening in Samliem, khon kaen, thailand? Asian Pac J Cancer Prev, 8, 353-6.

Demirtas B, Acikgoz I (2013). Promoting attendance at cervical cancer screening: understanding the relationship with Turkish womens' health beliefs. Asian Pac J Cancer Prev, 14, 333-40.

Erbil N, Tezcan Y, Gür EN, et al (2010). Factors affecting cervical screening among Turkish women. Asian Pac J Cancer Prev, 11, 1641-4.

Fang CY, Ma GX, Tan Y, et al (2007). A multifaceted intervention to increase cervical cancer screening among underserved Korean women. Cancer Epidemiol Biomarkers Prev, 16, 1298-302.

FernaAndez-Esquer ME, Espinoza P, Ramirez AG, et al (2003). Repeated Pap smear screening among mexican-american women. Health Educ Res, 18, 477-87.

Fry RB, Prentice-Dunn S (2006). Effects of a psychosocial intervention on breast self-examination attitudes and behaviors. Health Educ Res, 21, 287-95.

Gollwitzer PM, Brandstatter V (1997). Implementation intentions and effective goal pursuit. J Pers Soc Psychol, 73, 186-99.

Gollwitzer PM (1993). Goal achievement: the role of intentions. Eur Rev Soc Psychol, 4, 141-85.

Gu C, Chan CW, He GP, et al (2012). Chinese women's motivation to receive future screening: The role of socialdemographic factors, knowledge and risk perception of cervical cancer. Eur J Oncol Nurs, 17, 154-61.

Hassani L, Dehdari T, Hajizadeh E, et al (2014). Development of an instrument based on the protection motivation theory to measure factors influencing women's intention to first Pap test practice. Asian Pac J Cancer Prev, 15, 1227-32.

Helmes AW (2002). Application of the protection motivation theory to genetic testing for breast cancer risk. Prev Med, 35, 453-62.

Jelfs P (1995). Cervical cancer in australia. australian institute of health and welfare: cancer series No 3, AIHW, Canberra.

Markovic M, Kesic V, Topic L, et al (2005). Barriers to cervical cancer screening: a qualitative study with women in Serbia. Soc Sci Med, 61, 2528-35.

Mcmat B, Prentice-Dunn S (2005). Protection motivation theory and skin cancer risk: the role of individual differences in responses to persuasive appeals. J Appl Soc Psychol, 35, 621-43.

Milne S, Orbell S, Sheeran P(2002). Combining motivational and volitional interventions to promote exercise participation: Protection motivation theory and implementation intentions. Br J Health Psychol, 7, 163-84.

Mortazavi SH, Shahidi M, Shahrad B (2000). Changing trend in cancer incidence in iran. Cancer Strategy, 2, 13-6.

Othman NH, Devi BC, Halimah Y (2009). Cervical cancer screening: patients' understanding in major hospitals in Malaysia. Asian Pac J Cancer Prev, 10, 569-74.

Park S, Chang S, Chung C (2005). Effects of a cognitionemotion focused program to increase public participation in Papanicolaou smear screening. Public Health Nurs, 22, 289-98.

Rezaie-Chamani S, Mohammad-Alizadeh-Charandabi S, Kamalifard M (2012). Knowledge, attitudes and practice about Pap smear among women referring to a public hospital. J Family Reprod Health, 6, 177-82.

Rogers RW (1975). A protection motivation theory of fear appeals and attitude change. $J$ Psychology, 91, 93-114.

Rutter DR, Steadman L, Quine L (2006). An implementation intentions intervention to increase uptake of mammography. Ann Behav Med, 32, 127-34.

Shekhar S, Sharma C, Thakur S, et al (2013). Cervical cancer screening: knowledge, attitude and practices among nursing staff in a tertiary level teaching institution of rural India. Asian Pac J Cancer Prev, 14, 3641-5.

Sheeran P, Orbell S (2000) Using implementation intentions to increase attendance for cervical cancer screening. Health Psychol, 19, 283-9.

Steadman L, Quine L (2004). Encouraging young males to perform testicular self-examination: a simple, but effective, implementation intentions intervention. Br J Health Psychol, 9, 479-87.

Wongwatcharanukul L, PromthetS, Bradshaw P, et al (2014). Factors affecting cervical cancer screening uptake by among hilltribe women in Thailand. Asian Pac J Cancer Prev, 15, 3753-6.

Yucel U, Çeber E, Ozentürk G (2009). Efficacy of a training course given by midwives concerning cervical cancer risk factors and prevention. Asian Pac J Cancer Prev, 10, 437-42. 